\title{
Lipoprotein(a) as a Risk Factor for Venous Thromboembolism: A Systematic Review and Meta-analysis of the Literature
}

\author{
Francesco Dentali, MD ${ }^{1}$ Vera Gessi, MD ${ }^{1}$ Rossella Marcucci, MD ${ }^{2}$ Monica Gianni, MD ${ }^{3}$ \\ Anna Maria Grandi, MD ${ }^{1}$ Massimo Franchini, MD ${ }^{4}$
}

${ }^{1}$ Department of Clinical Medicine, Insubria University, Varese, Italy
${ }^{2}$ Department of Experimental and Clinical Medicine, University of
Florence, Firenze, Italy
${ }^{3}$ Cardiology Unit, Hospital of Tradate, Tradate, Italy
${ }^{4}$ Department of Hematology and Transfusion Medicine, Carlo Poma
Hospital, Mantua, Italy

Address for correspondence Francesco Dentali, MD, U.O. Medicina II, Ospedale di Circolo, Viale Borri 57, 21100 Varese, Italy (e-mail: fdentali@libero.it).

Semin Thromb Hemost

\begin{abstract}
Elevated plasma levels of lipoprotein(a) (Lp(a)) are associated with increased cardiovascular risk in several clinical studies. However, there is a lack of data supporting a positive association between elevated $\mathrm{LP}(\mathrm{a})$ levels and venous thromboembolism (VTE). Thus, we conducted a systematic review of the literature to better clarify its role as a risk factor for VTE. Medline and the Embase (up to May 2015) electronic databases were used to identify potentially eligible studies. Studies measuring $L P(a)$ values in adult patients with deep vein thrombosis and/or pulmonary embolism and in a population of patients without a VTE were selected. Studies on patients with major venous thromboembolic events occurring at other unusual site, case reports, and case series were excluded. The odds ratios (ORs) of the association between high values of Lp(a) and VTE and the weighted mean difference (WMD) in Lp(a) levels in cases and in controls were calculated using a random-effect model. Results were presented with $95 \%$ confidence interval $(\mathrm{Cl})$. Fourteen studies for a total of more than 14,000 patients were finally included in our analysis. LP(a) was slightly but significantly associated with

Keywords

- venous thromboembolism

- thrombosis

- lipoprotein(a) an increased risk of VTE (OR: 1.56, 95\% Cl: 1.36, 1.79; 10 studies, 13,541 patients). VTE patients had significantly higher $\mathrm{LP}(\mathrm{a})$ values compared with controls (WMD: 14.46 $\mathrm{mg} / \mathrm{L}, 95 \% \mathrm{Cl}: 12.14,16.78$; 4 studies, 470 patients). Lp(a) appeared to be significantly associated with increased risk of VTE. However, Lp(a) levels were only slightly increased in VTE patients compared with controls.
\end{abstract}

Lipoprotein(a) $(\mathrm{Lp}(\mathrm{a}))$ is a complex serum lipoprotein consisting of a low-density lipoprotein core associated by a disulfide bond with apolipoprotein(a), a heterogenous glycoprotein that, due to its structural homology with plasminogen, competes for fibrin binding, inhibits tissue plasminogen activator, and ultimately impairs fibrinolysis. ${ }^{1,2}$ It has been recognized that more than $90 \%$ of variation of plasma $\mathrm{LP}(\mathrm{a})$ concentration is genetically regulated, with apolipoprotein(a) gene (LPA) being a major determinant. To date, several genetic variants in the LPA gene have been shown to influence Lp(a) plasma values, rs3798220 and rs10455872 polymorphisms accounting in particular for at least $40 \%$ of such variation. ${ }^{3}$ Because of its dual nature (i.e., proatherosclerotic low-density lipoprotein-like and prothrombotic plasminogen-like), Lp(a) has been the subject of intense research over the past 20 years from both in vivo and in vitro studies that have analyzed its
Issue Theme Editorial Compilation IV; Guest Editors: Emmanuel J. Favaloro, PhD, FFSc (RCPA), and Giuseppe Lippi, MD.
Copyright $\odot$ by Thieme Medical Publishers, Inc., 333 Seventh Avenue, New York, NY 10001, USA. Tel: +1(212) 584-4662.
DOI http://dx.doi.org/ 10.1055/s-0036-1598002. ISSN 0094-6176. 
prothrombotic properties. ${ }^{4-6}$ Elevated plasma levels of $\mathrm{Lp}(\mathrm{a})$ were found to be associated with an increased cardiovascular risk in several retrospective and prospective clinical studies. ${ }^{1}$ Notably, a meta-analysis of almost 5,500 patients with coronary artery disease prospectively followed up for an average of 10 years reported that individuals with $\mathrm{Lp}(\mathrm{a})$ values in the top tertile had an approximately $70 \%$ increased risk of coronary artery disease events compared with individuals with values in the bottom tertile. ${ }^{7}$ Although convincing epidemiological evidences were brought forward to propose a causal role of $\mathrm{Lp}(\mathrm{a})$ in the development, progression, and complication of occlusive arterial disease, data supporting a positive association between elevated $\mathrm{Lp}(\mathrm{a})$ values and venous thromboembolism (VTE) are less consistent. A previous systematic review and meta-analysis of the literature conducted a decade ago and including a limited number of studies found a statistically significant, albeit modest, association between high Lp(a) ( $>300 \mathrm{mg} / \mathrm{L}$ ) and VTE (odds ratio [OR]: 1.87, 95\% confidence interval [CI]: $1.51-2.30) .{ }^{8}$ On the other hand, a more recent study reported an association between two variants of the LPA gene (rs10455872 and rs3798220 polymorphisms) and systemic and coronary atherosclerosis, but not with VTE. ${ }^{9}$ Therefore, to better clarify the role of $\mathrm{Lp}(\mathrm{a})$ as a risk factor for VTE, we conducted an extensive systematic review of the literature updating the results of the previous meta-analysis.

\section{Methods}

A protocol for this review was prospectively developed, detailing specific objectives, criteria for study selection, approach to assess study quality, outcomes, and statistical methods.

\section{Search Strategy}

Using the Medline and the Embase (up to May 2015) electronic databases without any language restriction, we identified all published studies that evaluated the role of $\operatorname{Lp}(a)$ as a potential risk factor for VTE. We supplemented our search by manually reviewing abstract books from the Congress of the International Society on Thrombosis and Haemostasis (ISTH) (2011-2015), and the reference lists of all retrieved articles, manually searching recent issues of thrombosis and hemostasis journals. Search results were reported according to Meta-analysis Of Observational Studies in Epidemiology (MOOSE) reporting guidelines. ${ }^{10}$

\section{Study Selection}

Two reviewers (V.G. and M.G.) performed the study selection independently, with disagreements solved through discussion and by the opinion of a third reviewer (F.D.) if necessary. Studies were considered potentially eligible for this systematic review if they met the following criteria: they included a population of patients with deep vein thrombosis (DVT) and/ or pulmonary embolism (PE) and a population of patients without a VTE (controls); Lp(a) values were measured in both patients with VTE and controls. Patients with major venous thromboembolic events at other unusual sites (e.g., splanchnic vein thrombosis and cerebral vein thrombosis) were not included in our systematic review. Furthermore, studies that only included patients with VTE recurrence were excluded. Finally, we did not include case reports, case series, and studies on patients younger than 18 years.

\section{Data Extraction}

Two reviewers (V.G. and M.G.) independently extracted data on study (year of publication, design) and population characteristics (number of patients, mean age, sex). Information on $\mathrm{Lp}(\mathrm{a})$ levels in VTE patients and in controls was also collected.

\section{Statistical Analysis and Risk of Bias Assessment}

Statistical analysis was performed using Review Manager (Version 5.2) provided by The Cochrane Collaboration (Copenhagen, Denmark). The ORs of the association between high values of $\mathrm{Lp}(\mathrm{a})$ and VTE and the weighted mean difference of $\mathrm{Lp}(\mathrm{a})$ values in case and in controls were calculated using a random-effect model. ${ }^{11}$ The overall effect was tested using Z-scores, and significance was set at $p<0.05$. Results were presented with $95 \% \mathrm{Cl}$. Statistical heterogeneity was evaluated using the $I^{2}$ statistic and the chi-square Cochrane Q test, which assess the appropriateness of pooling the individual study results. $^{12}$ Heterogeneity was considered significant when $p<0.10$. We also estimated the proportion of VTE in the population that could be attributed to elevated $\mathrm{Lp}(\mathrm{a})$ (populationattributable risk [PAR]) with the following formula:

$$
\mathrm{PAR}=100 \times[\text { Prevalence }(\text { OR-1)/Prevalence }(\mathrm{OR}-1)+1]
$$

For this calculation, we estimated the prevalence of exposure as frequency of elevated values of $\operatorname{Lp}(\mathrm{a})(>300 \mathrm{mg} / \mathrm{dL})$ among control subjects. Publication bias was graphically represented by funnel plots of the effect size versus the standard error.

\section{Results}

A total of 262 (90 Medline, 172 Embase) citations were

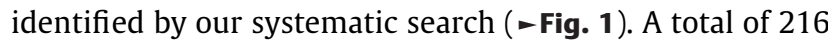
studies were excluded after title and abstract screening based on the predefined inclusion and exclusion criteria or because they were duplicates. Of the 32 studies retrieved in full text for more in-depth evaluation, 18 were excluded because they did not have a control group without VTE, did not provide information about the number of subjects with Lp(a) values above a pre-specified cut-off, they included children, or they considered patients with VTE other than DVT or PE (e.g., retinal vein occlusion). The interobserver for the study selection was perfect. Thus, 14 studies for a total number of 2,824 cases of VTE and 11,187 controls were included in our systematic review. ${ }^{13-26}$ Baseline characteristics of the included studies are summarized in - Table 1. Only one study provided separate data of patients with unprovoked VTE ${ }^{22}$ and two studies also included patients with two or more episodes of VTE $(15.5 \%$ in the study by Vormittag et al and 23\% in the study by Marcucci et al). ${ }^{18,22}$

Association between $\operatorname{Lp}(\mathrm{a})$ value and the risk of VTE was evaluated in 10 studies $^{13-22}$ for a total of 2,607 VTE patients 


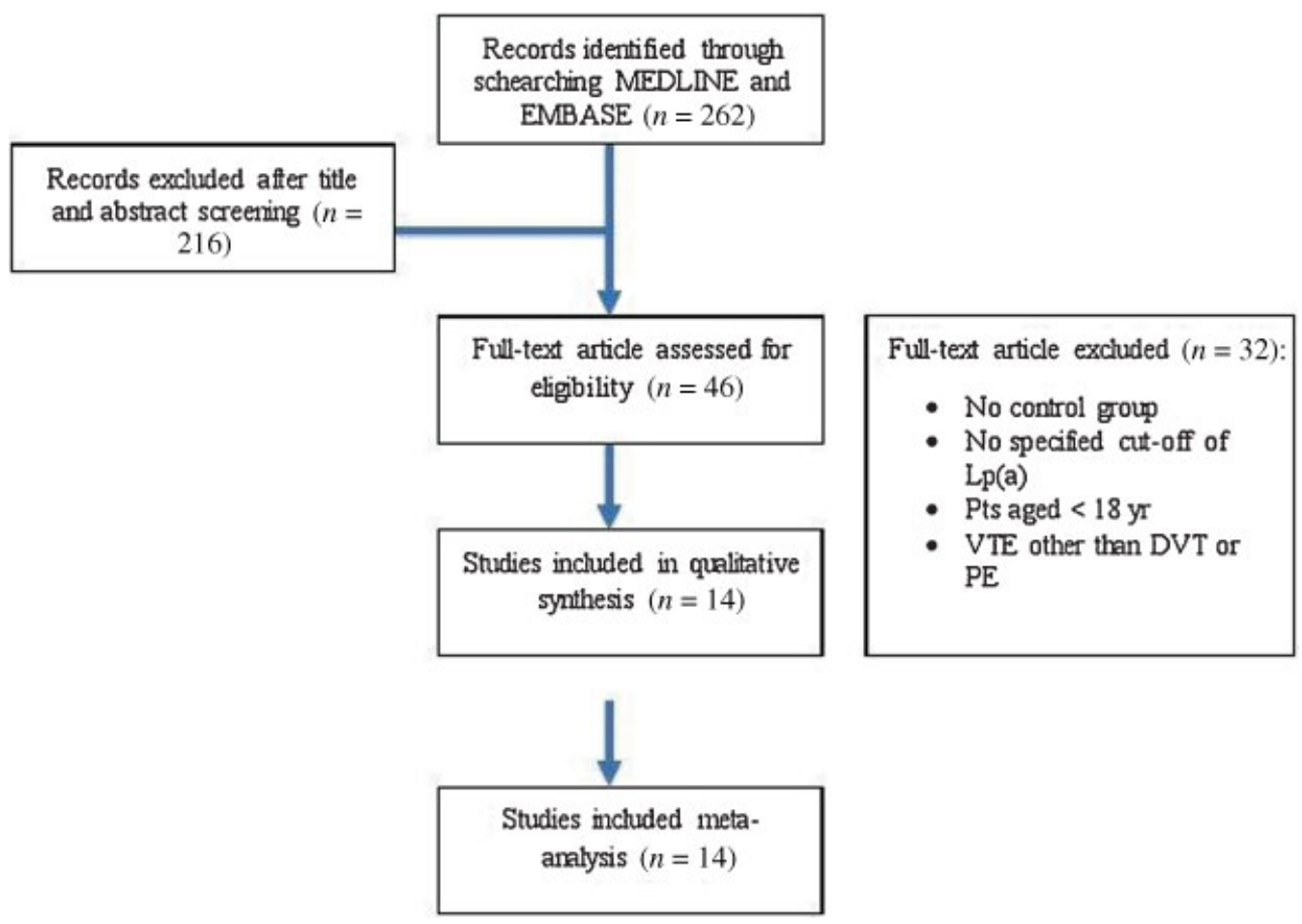

Fig. 1 Results of the systematic search.

and 10,934 controls. $\operatorname{Lp}(\mathrm{a})$ cut-off used for the analysis was the upper limit of the manufacturer's product reference range (usually $300 \mathrm{mg} / \mathrm{L}$ ) in nine studies ${ }^{13-16,18-22}$ and the 75th percentile of $\operatorname{Lp}(\mathrm{a})$ value in the control group in one study. ${ }^{14} \mathrm{Lp}(\mathrm{a})$ was significantly associated with an increased risk of VTE (OR: 1.56, 95\% CI: 1.36, 1.79; - Fig. 2). The estimated attributable risk of VTE conferred by elevated levels of $\operatorname{Lp}(\mathrm{a})$ was $19.8 \%$. Heterogeneity among studies was significant ( $I^{2}$ : 77\%, chi-square: $\left.39.67 ; p<0.001\right)$. Exclusion from the analysis of the study performed by Kamstrup et al significantly lowered the heterogeneity among the studies $\left(I^{2}: 56 \% ; p=0.02\right) .{ }^{16}$

The funnel plots of effect size versus standard error appeared symmetrical, suggesting the absence of publication bias (-Fig. 3).

Mean value of $\mathrm{Lp}(\mathrm{a})$ in cases and in controls was compared in four studies ${ }^{23-26}$ for a total of 470 patients (217 VTE patients and 253 controls). VTE patients had significantly higher Lp(a) levels compared with controls (WMD: 14.46 mg/L, 95\% CI: 12.14, 16.78; - Fig. 4). Heterogeneity among the studies was significant $\left(I^{2}\right.$ : $95 \%$, chi-square: 62.44 ; $p<0.001)$. Exclusion from the analysis of the study performed by Ogunyemi et al significantly lowered the heterogeneity $\left(I^{2}: 75 \%, p=0.02\right){ }^{25}$

\section{Discussion}

Many observations have pointed out that $L p(a)$ levels may be a risk factor for arterial cardiovascular and cerebrovascular diseases, by inhibiting the activation of transforming growth factor and contributing to the growth of arterial atheroscle- rotic lesions by promoting proliferation of vascular smooth muscle cells and migration of smooth muscle cells to endothelial cells. ${ }^{27}$ Furthermore, Lp(a) may act as a proinflammatory mediator, increasing the lesion formation in atherosclerotic plaques. ${ }^{27}$ Due to structural homology with plasminogen, this lipoprotein may also compete with plasminogen for its receptors on endothelial cells, thus leading to diminished plasmin formation, thereby delaying clot lysis and favoring venous thrombosis. ${ }^{28}$ However, evidence on its role as a risk factor for venous thromboembolic events remains controversial. ${ }^{29}$

Our meta-analysis, including data from 14 case-control studies for a total of 2,824 VTE patients and 11,187 healthy controls, showed a significant but only slight association between $\mathrm{Lp}(\mathrm{a})$ levels and VTE. The risk attributable to the presence of high levels of $\mathrm{Lp}(\mathrm{a})$ appeared globally modest (19.8\%) and the WMD in Lp (a) values in cases and in controls was only $14.46 \mathrm{mg} / \mathrm{L}$, a value that is likely composed of the analytical variability of the commercial immunoassays used for measuring $\operatorname{Lp}(\mathrm{a}) .^{30}$

In previous meta-analysis performed by Sofi et $a{ }^{8}{ }^{8}$ the presence of high $\operatorname{Lp}(\mathrm{a})$ values was significantly associated with increased risk of VTE. However, their results were based on six studies for a total of 1,786 VTE patients and 1,024 controls only, and they did not calculate the risk of VTE attributable to the presence of high $\operatorname{Lp}(\mathrm{a})$ values, nor did they evaluate the WMD of this parameter in cases and in controls.

In a previous large prospective study performed by Tsai et al, high values of $\operatorname{Lp}(\mathrm{a})$ were not found to be significantly associated with increased risk of developing VTE. ${ }^{31,32}$ The LITE study included 19,921 participants with no VTE history 


\begin{tabular}{|c|c|c|c|c|c|c|c|c|}
\hline 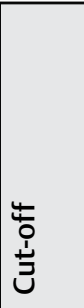 & 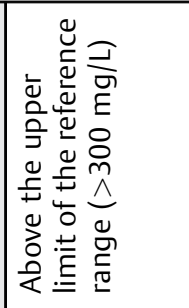 & 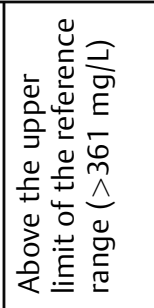 & 乏 & 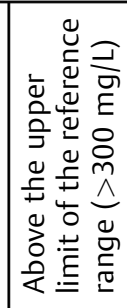 & 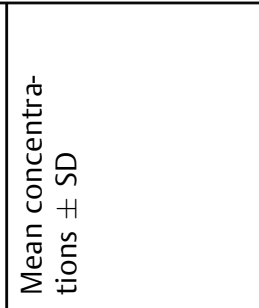 & 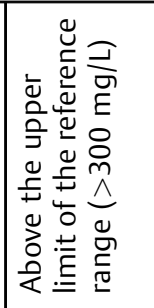 & 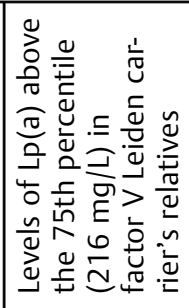 & 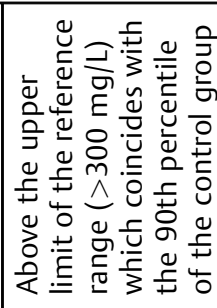 \\
\hline 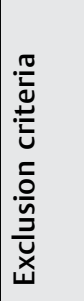 & & 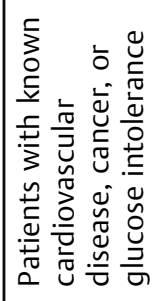 & & 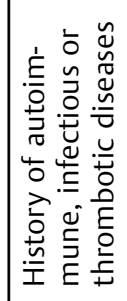 & 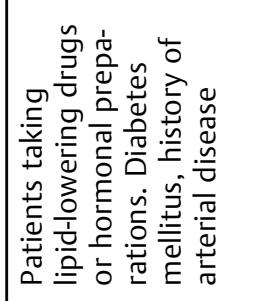 & 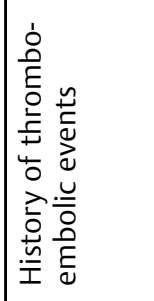 & & 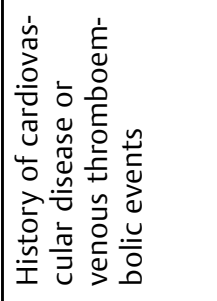 \\
\hline 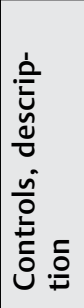 & 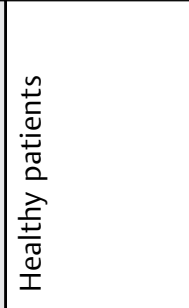 & 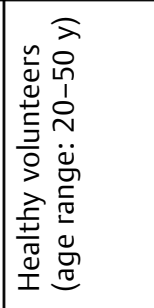 & 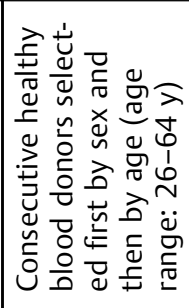 & 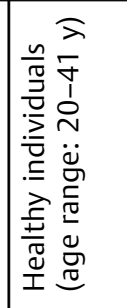 & 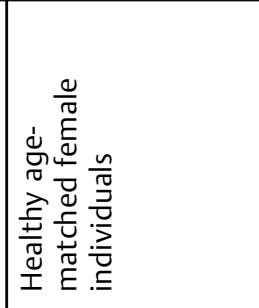 & 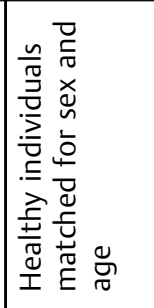 & 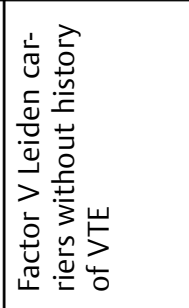 & 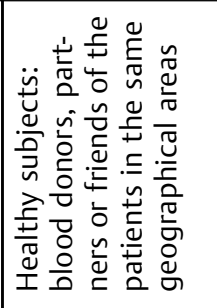 \\
\hline 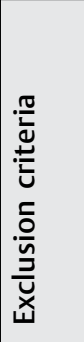 & 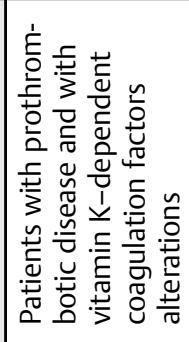 & 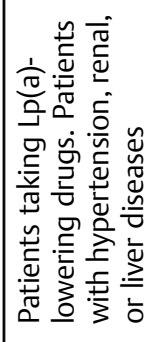 & & & 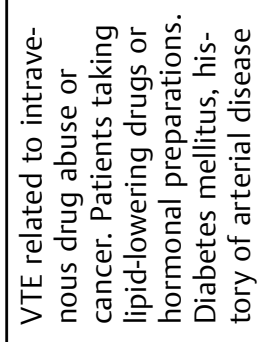 & 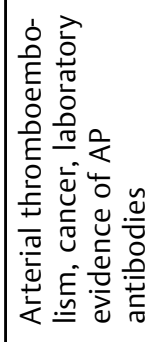 & & 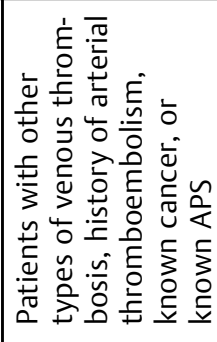 \\
\hline 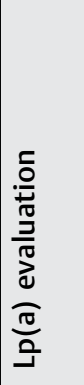 & 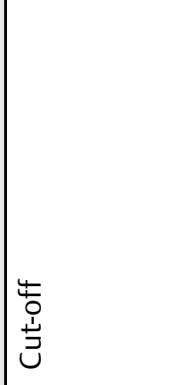 & 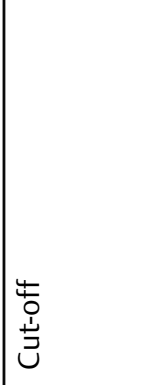 & 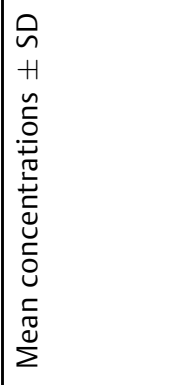 & 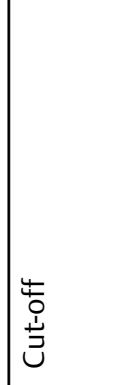 & 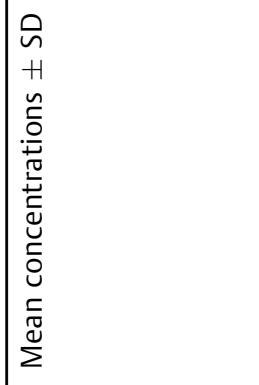 & 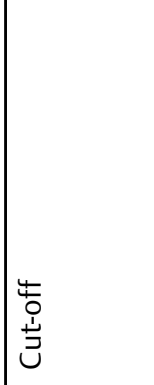 & 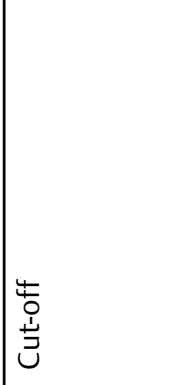 & 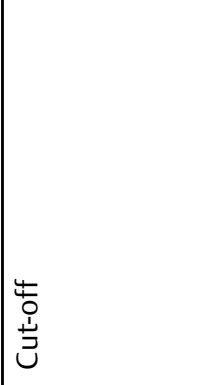 \\
\hline 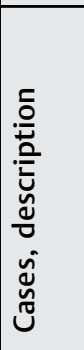 & 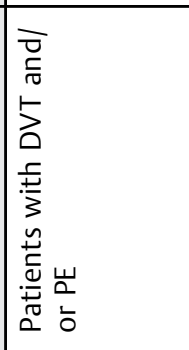 & 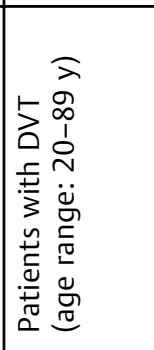 & 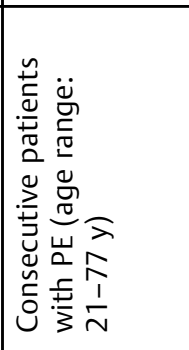 & 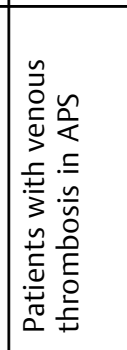 & 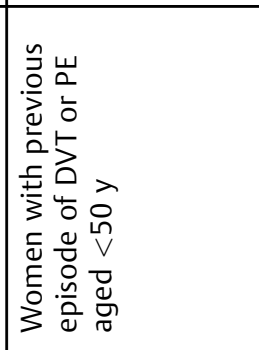 & 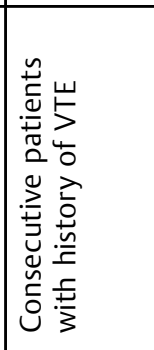 & 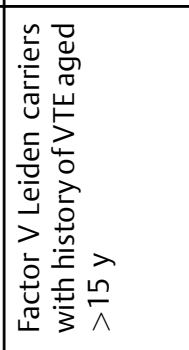 & 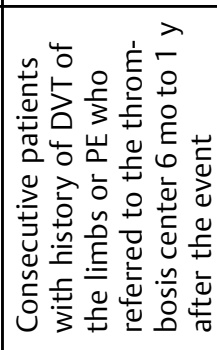 \\
\hline 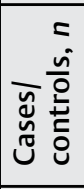 & $\frac{n}{\frac{n}{\tilde{m}}}$ & $\frac{\mathscr{g}}{\frac{\hat{m}}{m}}$ & $\stackrel{\stackrel{n}{\stackrel{N}{N}}}{\stackrel{\omega}{\sim}}$ & $\frac{\mathbb{N}}{\frac{N}{m}}$ & $\frac{\infty}{\frac{\infty}{\sigma}}$ & 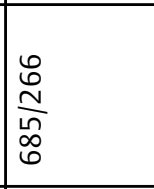 & 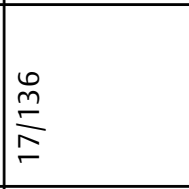 & $\frac{\stackrel{\rho}{\tilde{m}}}{\frac{\tilde{m}}{\tilde{\theta}}}$ \\
\hline 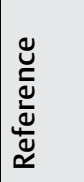 & 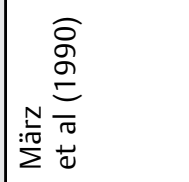 & 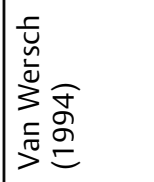 & 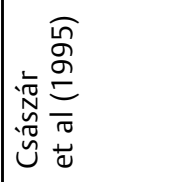 & 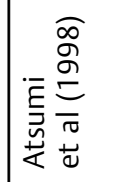 & 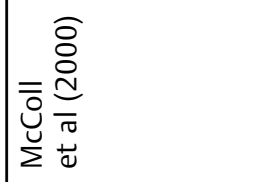 & 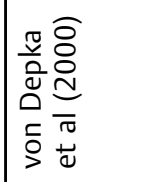 & 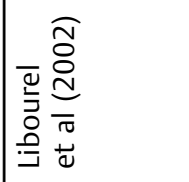 & 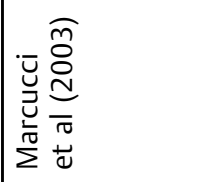 \\
\hline
\end{tabular}




\begin{tabular}{|c|c|c|c|c|c|c|}
\hline 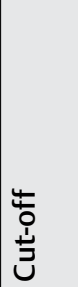 & 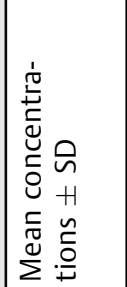 & 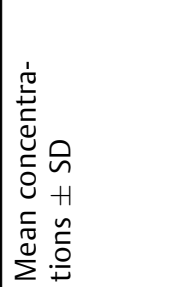 & 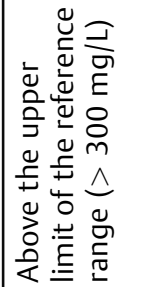 & 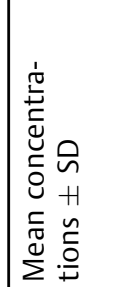 & 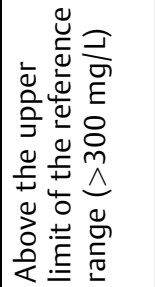 & 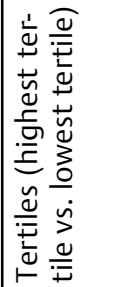 \\
\hline 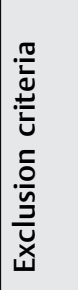 & & 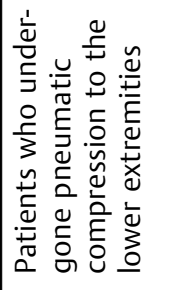 & 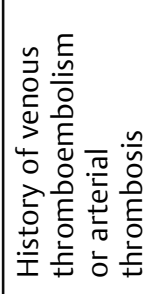 & & 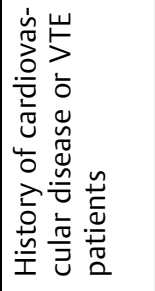 & \\
\hline 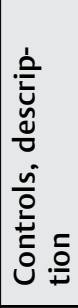 & 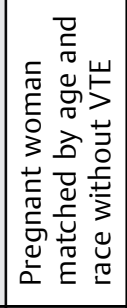 & 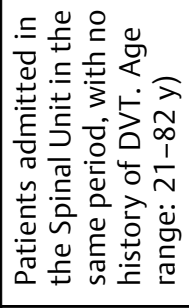 & 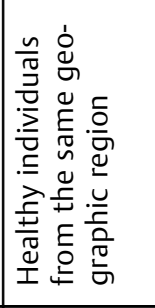 & 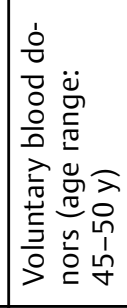 & 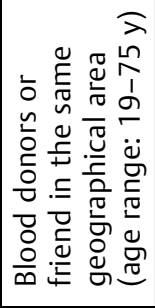 & 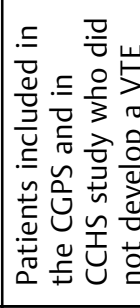 \\
\hline 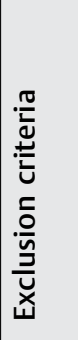 & & 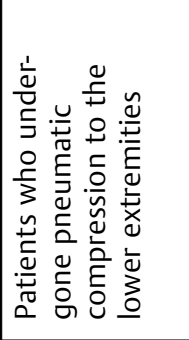 & 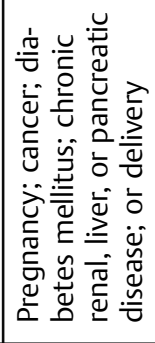 & & 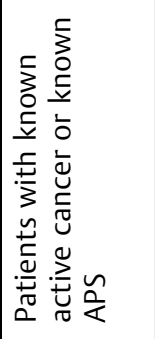 & \\
\hline 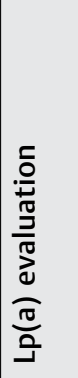 & 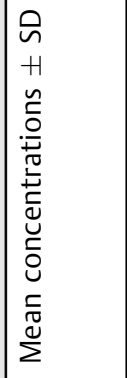 & 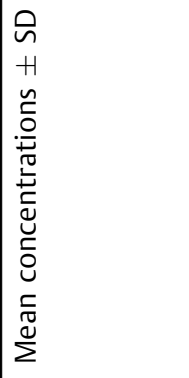 & 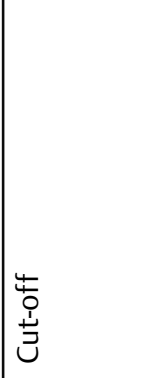 & 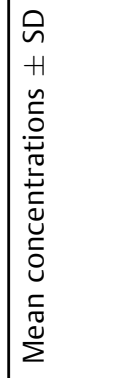 & 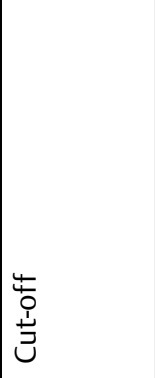 & 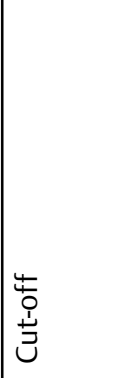 \\
\hline 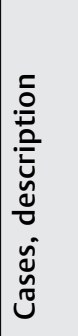 & 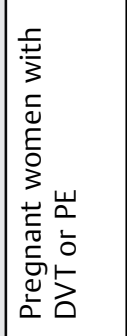 & 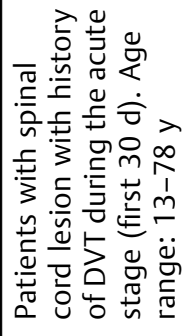 & 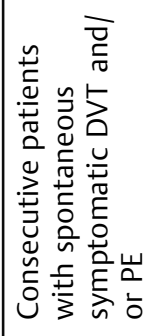 & 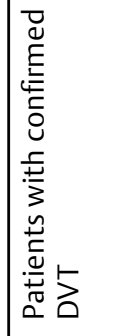 & 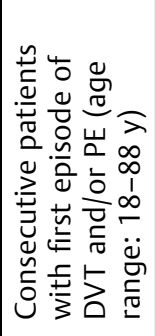 & 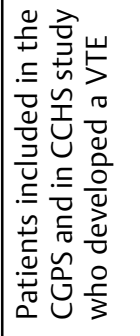 \\
\hline 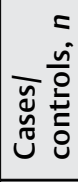 & $\frac{\stackrel{\rho}{m}}{\frac{m}{m}}$ & $\frac{\dot{q}}{\dot{q}}$ & 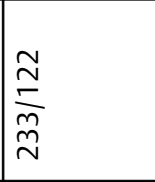 & $\frac{8}{\frac{0}{8}}$ & 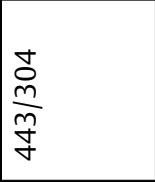 & 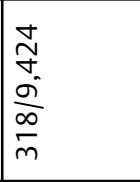 \\
\hline 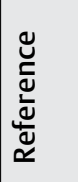 & 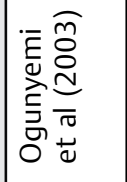 & 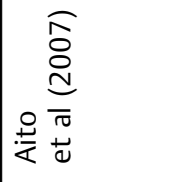 & 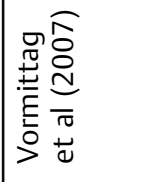 & 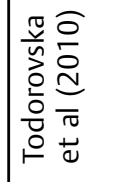 & 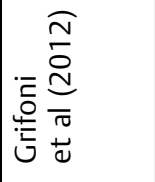 & 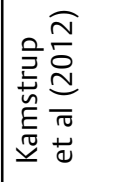 \\
\hline
\end{tabular}




\begin{tabular}{|c|c|c|c|c|c|c|c|c|c|c|}
\hline Study or Subgroup & $\begin{array}{l}\text { VTE pat } \\
\text { Events }\end{array}$ & $\begin{array}{l}\text { ents } \\
\text { Total }\end{array}$ & \multicolumn{2}{|c|}{ Control group } & Weight & $\begin{array}{c}\text { Odds Ratio } \\
\text { M-H, Fixed, } 95 \% \mathrm{Cl}\end{array}$ & \multicolumn{4}{|c|}{$\begin{array}{c}\text { Odds Ratio } \\
\text { M-H, Fixed, } 95 \% \mathrm{Cl}\end{array}$} \\
\hline Aito, 2007 & 9 & 43 & 6 & 46 & $1.4 \%$ & $1.76[0.57,5.46]$ & & & & \\
\hline Atsumi, 1998 & 13 & 31 & 3 & 22 & $0.6 \%$ & $4.57[1.12,18.76]$ & & & & \\
\hline Grifoni, 2012 & 139 & 443 & 45 & 304 & $11.0 \%$ & $2.63[1.81,3.83]$ & & & 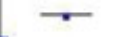 & \\
\hline Kamstrup, 2012 & 159 & 318 & 4695 & 9424 & $45.9 \%$ & $1.01[0.81,1.26]$ & & & & \\
\hline Libourel, 2002 & 6 & 17 & 30 & 136 & $1.3 \%$ & $1.93[0.66,5.64]$ & & & & \\
\hline Marcucci, 2003 & 146 & 603 & 58 & 430 & $15.4 \%$ & $2.05[1.47,2.86]$ & & & $\rightarrow$ & \\
\hline Marz, 1990 & 56 & 203 & 30 & 115 & $8.3 \%$ & $1.08[0.64,1.81]$ & & & & \\
\hline Van Wersch, 1994 & 1 & 31 & 7 & 69 & $1.3 \%$ & $0.30[0.03,2.51]$ & & & & \\
\hline von Depka, 2000 & 135 & 685 & 19 & 266 & $6.6 \%$ & $3.19[1.93,5.28]$ & & & $\longrightarrow$ & \\
\hline Vormittag, 2007 & 72 & 233 & 31 & 122 & $8.4 \%$ & $1.31[0.80,2.15]$ & & & - & \\
\hline Total $(95 \% \mathrm{CI})$ & & 2607 & & 10934 & $100.0 \%$ & $1.56[1.36,1.79]$ & & & 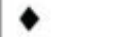 & \\
\hline Total events & 736 & & 4924 & & & & & & & \\
\hline $\begin{array}{l}\text { Heterogeneity: } \mathrm{Chi}^{2}= \\
\text { Test for overall effect }\end{array}$ & $\begin{array}{l}39.67, \mathrm{df} \\
Z=6.30\end{array}$ & $\begin{array}{l}=9(P \\
P<0 . C\end{array}$ & $\begin{array}{l}<0.0000 \\
00001)\end{array}$ & ) $; 1^{2}=$ & & & 0.01 & $\begin{array}{c}0.1 \\
\text { Decreased risk of VTE }\end{array}$ & Increased $\mathrm{ri}$ & 10 \\
\hline
\end{tabular}

Fig. 2 Forrest plot evaluating the association between elevated levels of $\mathrm{LP}(\mathrm{a})$ and the risk of VTE. Cl, confidence interval.

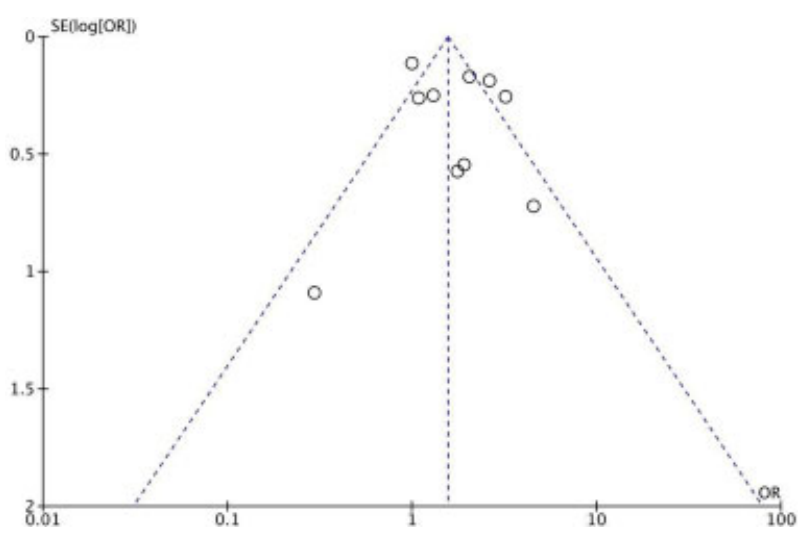

Fig. 3 Funnel plots of effect size versus standard error evaluating the presence of publication bias.

at baseline, were not taking warfarin, and had $\operatorname{Lp}(\mathrm{a})$ measured. The age and sex-adjusted hazard ratio for $\mathrm{Lp}$ (a) $>300 \mathrm{mg} / \mathrm{L}$ versus $\leq 300 \mathrm{mg} / \mathrm{L}$ was 1.12 (95\% CI: $0.55-2.27$ ) for whites and 1.31 (95\% CI: 0.69-2.47) for blacks, thus suggesting that the association between elevated $\mathrm{Lp}(\mathrm{a})$ and VTE was likely modest, if any.

Furthermore, $\operatorname{Lp}(\mathrm{a})$ appeared to have a limited role in identifying patients at high risk of VTE recurrence. In a quite large prospective study, elevated $\mathrm{Lp}(\mathrm{a})$ levels do not appear to be associated with recurrent VTE in patients with history of unprovoked VTE, ${ }^{33}$ and no study has demonstrated that Lp (a)-lowering therapy might be beneficial in reducing the incidence of VTE recurrence, at least in some subgroups of patients with high $\mathrm{Lp}(\mathrm{a})$ levels.
Therefore, the results of our meta-analysis confirm the questionable role of $\mathrm{Lp}(\mathrm{a})$ as a risk factor for VTE. Overall, $\mathrm{Lp}$ (a) appeared a weak risk factor for venous thrombosis, so that its extensive evaluation outside the context of clinical research in patients with a previous VTE does not appear justified, also considering that the current methods available on the market are quite expensive.

Our meta-analysis has several potential limitations. First, the application of formal meta-analytic methods to observational studies is controversial, because inherent bias in the study design may misrepresent the strength of associations within data. ${ }^{10}$ To minimize this potential bias, we included only studies in which the diagnosis of venous thromboembolic event was objectively confirmed. Second, studies included in our meta-analysis have different inclusion and exclusion criteria, and to combine results across studies may be inappropriate. Furthermore, the heterogeneity among the studies was significant, suggesting caution in the interpretation of the results. Different study design and difference in the population evaluated (e.g., pregnant patients) may explain heterogeneity among the studies. Another important drawback is the use of different methods for measuring $\operatorname{Lp}(\mathrm{a})$, each of which displays different performance due to the heterogeneity of the molecule being measured. Due to the lack of universal standard and reference antibodies, the size effects of larger or different isoforms may lead to conflicting conclusions when pooling data. ${ }^{34}$ However, we decided to combine our results using the random-effect model, an approach that takes into account the variance among the studies. Third, due to the limits of a study-level meta-analysis, we were not able to

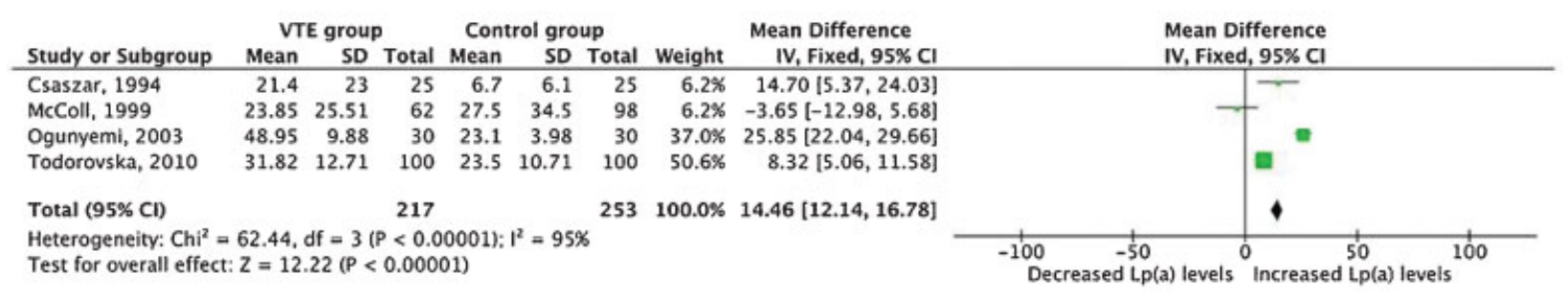

Fig. 4 Forrest plot evaluating the weighted mean difference in LP(a) levels in VTE cases and in controls. CI, confidence interval. 
adjust our results for these potential risk factors; therefore, we could not analyze the association with specific subgroup of patients (e.g., patients with unprovoked VTE). Finally, although an extensive research of the literature was performed and the funnel plots of effect size versus standard error appeared symmetrical, the presence of publication bias, albeit extremely unlikely, could not be definitively excluded.

In conclusion, $\operatorname{Lp}(\mathrm{a})$ appeared to be significantly associated with increased risk of VTE. However, $L p(a)$ levels were only slightly increased in VTE patients compared with controls and the heterogeneity of the analytical techniques is still a cause for large bias. Thus, an extensive evaluation of this parameter in all the patients with a previous VTE does not appear justified. Other prospective studies evaluating the role of $\mathrm{Lp}(\mathrm{a})$-specific subgroups of patients with VTE (e.g., patients with an unprovoked event) are still warranted.

\section{References}

1 Lippi G, Guidi G. Lipoprotein(a): an emerging cardiovascular risk factor. Crit Rev Clin Lab Sci 2003;40(1):1-42

2 Franchini M, Veneri D, Salvagno GL, Manzato F, Lippi G. Inherited thrombophilia. Crit Rev Clin Lab Sci 2006;43(3):249-290

3 Clarke R, Peden JF, Hopewell JC, et al; PROCARDIS Consortium. Genetic variants associated with $\mathrm{Lp}(\mathrm{a})$ lipoprotein level and coronary disease. N Engl J Med 2009;361(26):2518-2528

4 Spence JD, Koschinsky M. Mechanisms of lipoprotein(a) pathogenicity: prothrombotic, proatherosclerotic, or both? Arterioscler Thromb Vasc Biol 2012;32(7):1550-1551

5 Tsimikas S, Hall JL. Lipoprotein(a) as a potential causal genetic risk factor of cardiovascular disease: a rationale for increased efforts to understand its pathophysiology and develop targeted therapies. J Am Coll Cardiol 2012;60(8):716-721

6 Durrington PN, Schofield JD, Siahmansur T, Soran H. Lipoprotein (a): gene genie. Curr Opin Lipidol 2014;25(4):289-296

7 Danesh J, Collins R, Peto R. Lipoprotein(a) and coronary heart disease. Meta-analysis of prospective studies. Circulation 2000; 102(10):1082-1085

8 Sofi F, Marcucci R, Abbate R, Gensini GF, Prisco D. Lipoprotein (a) and venous thromboembolism in adults: a meta-analysis. Am J Med 2007;120(8):728-733

9 Helgadottir A, Gretarsdottir S, Thorleifsson G, et al. Apolipoprotein(a) genetic sequence variants associated with systemic atherosclerosis and coronary atherosclerotic burden but not with venous thromboembolism. J Am Coll Cardiol 2012;60(8):722-729

10 Stroup DF, Berlin JA, Morton SC, et al. Meta-analysis of observational studies in epidemiology: a proposal for reporting. Metaanalysis Of Observational Studies in Epidemiology (MOOSE) group. JAMA 2000;283(15):2008-2012

11 DerSimonian R, Laird N. Meta-analysis in clinical trials. Control Clin Trials 1986;7(3):177-188

12 Higgins JP, Thompson SG, Deeks JJ, Altman DG. Measuring inconsistency in meta-analyses. BMJ 2003;327(7414):557-560

13 Aito S, Abbate R, Marcucci R, Cominelli E. Endogenous risk factors for deep-vein thrombosis in patients with acute spinal cord injuries. Spinal Cord 2007;45(9):627-631

14 Atsumi T, Khamashta MA, Andujar C, et al. Elevated plasma lipoprotein(a) level and its association with impaired fibrinolysis in patients with antiphospholipid syndrome. J Rheumatol 1998; 25(1):69-73
15 Grifoni E, Marcucci R, Ciuti G, et al. The thrombophilic pattern of different clinical manifestations of venous thromboembolism: a survey of 443 cases of venous thromboembolism. Semin Thromb Hemost 2012;38(2):230-234

16 Kamstrup PR, Tybjærg-Hansen A, Nordestgaard BG. Genetic evidence that lipoprotein(a) associates with atherosclerotic stenosis rather than venous thrombosis. Arterioscler Thromb Vasc Biol 2012;32(7):1732-1741

17 Libourel EJ, Bank I, Meinardi JR, et al. Co-segregation of thrombophilic disorders in factor V Leiden carriers; the contributions of factor VIII, factor XI, thrombin activatable fibrinolysis inhibitor and lipoprotein(a) to the absolute risk of venous thromboembolism. Haematologica 2002;87(10):1068-1073

18 Marcucci R, Liotta AA, Cellai AP, et al. Increased plasma levels of lipoprotein(a) and the risk of idiopathic and recurrent venous thromboembolism. Am J Med 2003;115(8):601-605

19 März W, Aygören E, Trommlitz M, Scharrer I, Gross W. Lipoprotein (a): an indicator of risk in thromboembolic disease? [in German]. Klin Wochenschr 1990;68(Suppl (Suppl 22):111-112

20 Van Wersch JW. The behaviour of lipoprotein(a) in patients with various diseases. Scand J Clin Lab Invest 1994;54(7):559-562

21 von Depka M, Nowak-Göttl U, Eisert R, et al. Increased lipoprotein (a) levels as an independent risk factor for venous thromboembolism. Blood 2000;96(10):3364-3368

22 Vormittag R, Vukovich T, Stain M, Lehr S, Minar E, Pabinger I. Lipoprotein (a) in patients with spontaneous venous thromboembolism. Thromb Res 2007;120(1):15-20

23 Császár A, Karádi I, Juhász E, Romics L. High lipoprotein(a) levels with predominance of high molecular weight apo(a) isoforms in patients with pulmonary embolism. Eur J Clin Invest 1995;25(5):368-370

24 McColl MD, Sattar N, Ellison J, et al. Lipoprotein (a), cholesterol and triglycerides in women with venous thromboembolism. Blood Coagul Fibrinolysis 2000;11(3):225-229

25 Ogunyemi D, Cuellar F, Ku W, Arkel Y. Association between inherited thrombophilias, antiphospholipid antibodies, and lipoprotein A levels and venous thromboembolism in pregnancy. Am J Perinatol 2003;20(1):17-24

26 Todorovska E, Blagoevska M, Dimitrovski K, Makarosvka Bojadzieva T, Dukovski R. Lipid and fibrinolytic dysbalance between patients with deep venous thrombosis. Vox Sanguinis 2010(99, Suppl 1):438

27 Malaguarnera M, Vacante M, Russo C, et al. Lipoprotein(a) in cardiovascular diseases. BioMed Res Int 2013;2013:650989

28 Hajjar KA, Nachman RL. The role of lipoprotein(a) in atherogenesis and thrombosis. Annu Rev Med 1996;47:423-442

29 Lippi G, Bassi A, Brocco G, Manzato F, Marini M, Guidi G. Lipoprotein(a) concentration is not associated with venous thromboembolism in a case control study. Haematologica 1999;84(8):726-729

30 Lippi G, Guidi G. Standardization and clinical management of lipoprotein(a) measurements. Clin Chem Lab Med 1998;36(1): 5-16

31 Tsai AW, Cushman M, Rosamond WD, Heckbert SR, Polak JF, Folsom AR. Cardiovascular risk factors and venous thromboembolism incidence: the longitudinal investigation of thromboembolism etiology. Arch Intern Med 2002;162(10):1182-1189

32 Folsom AR, Chamberlain A. Lipoprotein(a) and venous thromboembolism. Am J Med 2008;121(2):e17, author reply e19

33 Rodger MA, Le Gal G, Carrier M, et al. Serum lipoprotein (a) levels in patients with first unprovoked venous thromboembolism is not associated with subsequent risk of recurrent VTE. Thromb Res 2010;126(3):222-226

34 Lippi G, Franchini M, Targher G. Screening and therapeutic management of lipoprotein(a) excess: review of the epidemiological evidence, guidelines and recommendations. Clin Chim Acta 2011;412(11/12):797-801 